\title{
Molecular evidence indicates the existence of multiple lineages of Sperata in Indian Rivers
}

\section{Prabhaker Yadav}

Wildlife Institute of India

\section{Ajit Kumar \\ Wildlife Institute of India \\ Neha Yadav \\ Wildlife Institute of India \\ Mansi Bisht \\ Wildlife Institute of India}

\author{
Anuja Mital \\ Odum School of Ecology, University of Georgia, Athens, GA, USA \\ Jeyaraj Antony Johnson \\ Wildlife Institute of India

\section{Syed Ainul Hussain} \\ Wildlife Institute of India \\ Sandeep Gupta ( $\nabla$ skg@wii.gov.in ) \\ Wildlife Institute of India
}

\section{Research Article}

Keywords: evolutionarily significant units, genetic structure, Indian rivers, mitochondrial DNA, phylogenetics

Posted Date: February 15th, 2022

DOI: https://doi.org/10.21203/rs.3.rs-1271404/v1

License: (c) (i) This work is licensed under a Creative Commons Attribution 4.0 International License. Read Full License 


\section{Abstract}

Understanding the population genetic structure and species boundaries in the complex river system has been challenging. The genus Sperata, a commercially important and widely distributed freshwater catfishes of India, belongs to Bagridae. The taxonomy of the Sperata genus is complex and still under revision. Recently, five valid species of Sperata were described from the Indian subcontinent. To determine the species boundaries and presence of taxonomic units within the Spereta, we analyzed the sequences of mitochondrial DNA (mtDNA) cytochrome c oxidase I (COI) and control region (CR) from Ganga, Gomti, Brahmaputra and Mahanadi river. The analysis of species delimitation using the $\mathrm{CO} /$ gene indicated the presence of multiple taxonomic units among Sperata. Similarly, CR suggested the high haplotype diversity in S. lamarrii with a signature of demographic expansion in the Ganga river. In this study, we identified S. cf. lamarrii, a new lineage from the lower stretch of Ganga, another Sperata sp. from the Brahmaputra, Surma (Bangladesh) river, and from an unknown locality. It also highlighted that the Brahmaputra river also holds a highly diverse lineage that genetically qualifies the status of distinct species. Our finding suggests that multiple lineages of Sperata existed in the Indian River system; therefore, these should be considered a different management unit to protect contamination of natural stock. This study can be further used as a reference database for proper lineage identification within Sperata to formulate appropriate conservation and management plans.

\section{Introduction}

The genus Sperata is a giant catfish that belongs to the family Bagridae and is widely distributed in South Asia, mainly occurring in major river systems of India, Pakistan, Bangladesh, Afghanistan, Myanmar and Nepal1,2,3. Due to high nutritional values and the low number of intramuscular bones, Sperata species have huge demand in South Asian countries $^{4}$. It is recognized as one of the commercially important catfish species ${ }^{5,6}$. The taxonomy of Sperata genus is complex and previously assigned to various genus Bagrus, Platystoma, Macrones, Mystus, Osteobagrus, Aorichthys, and Sperata. Based on the morphological characteristics, different Sperata species have been described by Day (1878), Talwar \& Jhingran (1991), Chondar (1999) and Ferraris and Runge (1999). With the increasing number of studies on freshwater fish, the number of newly recognized Sperata species is also increasing. Ferraris \& Runge (1999) identified four species under the genus Sperata i.e., S. seenghala (Sykes, 1839), S. aor (Hamilton, 1822), S. acicularis (Ferraris \& Runge, 1999), and S. aorella (Blyth, 1858) from South Asia. Recently, five valid species of Sperata from the Indian subcontinent ${ }^{3}$. Sperata lamarrii is now considered a valid species from the Ganges-Brahmaputra basin, earlier reported as $S$. seenghala by many researchers ${ }^{7,8}$. $S$. aorides, endemic to the Cauvery river basin and $S$. seenghala endemic to the Krishna river basin, are restricted to peninsular Indian rivers south of the Godavari. S. aor and S. aorella are widely distributed in the Ganges-Brahmaputra-Surma river basins in India and Bangladesh. In addition, S. aor was also recorded from Godavari and Narmada river basin ${ }^{3}$. The $S p e r a t a$ $s p$. native to the Indus river basin identified as a sub-species Aorichthys aor sarwari, and further treated as a valid species $S$. sarwari $\left.{ }^{2,9,10}\right)$. S. sarwari was closer to $S$. seenghala; hence it is placed in the synonymy of $S$. seenghala ${ }^{2}$. Recently, with the revision of $S$. seenghala to $S$. lamarrii by Kumar et al. (2021), $S$. sarwari is also considered as $S$. lamarrii. Moreover, $S$. acicularis is widely distributed in the Irrawaddy basin in Myanmar².

The catfish can tolerate a high range of temperature $\left(38-40^{\circ} \mathrm{C}\right)$, low dissolved oxygen, and salinity along with variable water conditions because of their robust air-breathing system ${ }^{11,12}$. Among the five species of the genus Sperata, $S$. Iamarrii (the giant river-catfish) and $S$. aor (the long-whiskered catfish) have a wide distribution in the Indian subcontinent ${ }^{3,13}$. The giant river-catfish and $S$. the long-whiskered catfish are recognized as "least concern" in the RedList of International Union for Conservation of Nature (IUCN).

In the Ganga river, the high anthropogenic activities such as extensive fishing, water abstraction, pollution, siltation, and invasion of exotic species are threatening the Sperata populations. Hence, understanding the genetic structure of exploited fish populations is crucial for the sustainable management of fishery resources ${ }^{14}$. Previous studies on giant river catfish gradually focused on the genetic assessment of $S$. seenghala using Randomly amplified polymorphic DNA (RAPD) 
marker ${ }^{15,16}$, mitochondrial DNA (mtDNA) markers ${ }^{7}$, and microsatellite marker ${ }^{8}$. The microsatellite-based stock discrimination of $S$. aor revealed the existence of three genetic stocks from the connected vicinity of the Ganga river ${ }^{17}$. Despite being significant variations, the identification between Spereta species is quite tricky. Hence, extensive sampling is essential to resolve the population genetic structure and validate lineage's existence. With this, an appropriate management plan for a different stock can be prepared by incorporating reliable knowledge about existing lineages from species distribution ranges.

Due to the maternal mode of transmission, and more rapid evolution than the nuclear genome, mtDNA provides reliable information on the relationships among closely related species and populations ${ }^{18}$. The mtDNA cytochrome oxidase (CO/) gene is a suitable genomic region used as a DNA barcode to delimit species and for any taxonomic inconsistencies ${ }^{19}$. In particular, the mtDNA control region (CR) is a highly variable portion and estimated to be five times more substitution rate than that of the rest sequences in $\mathrm{mtDNA}^{20}$. For this reason, these genetic markers are widely acceptable for population genetics studies ${ }^{21,22}$

In this study, we tested the analytical power of the CO/gene in species discrimination in the Sperata genus. Subsequently, mtDNA CR sequences were deployed to assess the population genetic structure of Spereta species from major river systems of India.

\section{Results}

\section{mtDNA CO/analysis}

We generated a $621 \mathrm{bp}$ fragment of the CO/ gene from 270 samples for identifying the species boundaries and presence of taxonomic units within the Spereta. To support our analysis, we included the confirmed 19 Spereta sequences from GenBank ${ }^{3,8,23}$. The analyzed sequences resulted in 32 haplotypes and different numbers of individuals were observed in each haplotype (Table ST2). Of these, 12 haplotypes (Hap 1 to Hap 12) were observed in S. lamarrii from Ganga, Gomti, Hooghly and Brahmaputra. One haplotype (Hap 15) represents the sequences of $S$. seenghala from the Tunga and Krishna rivers. Five haplotypes (Hap 21 to Hap 25) were observed in S. aorella recorded from the lower stretch of Ganga, Brahmaputra and Hooghly river. Single haplotype (Hap 26) was observed in S. aorides in the Cauvery river, whereas six haplotypes (Hap 27 to Hap 32) were observed in Sperata aor from the Ganga and Hooghly rivers.

Additionally, two newly identified haplotypes (Hap 13 to Hap 14) were observed in the Ganga river from Bihar and Jharkhand region, showed distinct genetic signatures with S. lamarrii. In contrast, five haplotypes (Hap16 to Hap 20) observed in the Brahmaputra, Surma (Bangladesh) and unknown localities showed distinct genetic signatures with $S$. seenghala and we named these as Spereta spp. (previously represented as S. cf. seenghala by Kumar et al., 2021).

\section{Species delimitation}

Species delimitation using five unique methods (mPTP, bPTP, GMYC, ABGD and ASAP) were analysed (Figure 2). The three model mPTP, ABGD and ASAP indicated the presence of seven species in our dataset, whereas bPTP and GMYC analysis indicated nine putative species. All analyses delimited the species boundary as inferred from the clustering pattern of phylogenetic analysis, namely: S. lamarrii, S. cf. lamarrii, S. seenghala, Spereta sp., S. aorella, S. aorides, and S. aorwhile the bPTP and GMYC model additionally expanded the Spereta sp. and $S$. aor into 2 subsets. The result of the three models (mPTP, ABGD and ASAP) supported the previously recognized taxonomic divisions, corroborating our analyses. The GYMC and bPTP model splits Spereta sp. into two groups: e.g., the single sequence S. seenghala (KT762382) from the Surma river in Bangladesh and four sequences (KU588160, KU588161, KU588164, KU588165) from unknown locations formed one group, whereas the two sequences (SS243 and SS244) from the Brahmaputra in Tezpur, Assam splits further. Within the $S$. aor, the GMYC model splits a single haplotype (Hap 31) as a distinct subgroup. The GMYC results suggest a disproportionate number of 9 clusters (confidence interval: $3-11$ species, the maximum likelihood of null model $=336.9802$; 
the maximum likelihood of GMYC model $=342.742$; threshold time $=-0.002$ ). Therefore, the three mPTP, ABGD and ASAP analyses are consistent with the existence of the seven different species of Sperata.

We calculated inter-specific and intra-specific mean pairwise genetic distances for all Spereta lineages (Table 1). The divergence between the recognized species ranged from $1.5 \%$ for $S$. lamarrii and $S$. seenghala to $10 \%$ for $S$. aorides and $S$. aor. The divergence between $S$. lamarri and S. cf. lamarri was $1.7 \%$ and it was $1.8 \%$ for Sperata $s p$. and $S$. seenghala. These values were more pronounced than observed interspecific divergence for recognized species. An intra-specific pairwise distance was ranged from 0.00 for $S$. seenghala to $0.4 \%$ for Sperata $s p$.

\section{mtDNA CR sequence polymorphism and haplotype diversity}

We obtained 835 bp sequences of CR from 270 samples of Speratafrom 13 different locations covering major rivers Ganga, Brahmaputra and Gomti (Figure 1; Table 1). In addition, 75 GenBank sequences were included from Ganga ( $n=25)$, Mahanadi ( $n=25)$, and Brahmaputra ( $n=25)$ rivers (Table ST1). Thus, 345 sequences were analyzed, resulting in 91 haplotypes (Table ST3).

Out of these, 44 haplotypes (Hap1 to Hap 44) were observed in S. Iamarrii(Lineage 1, L1) from the Ganga, Gomti, and Brahmaputra rivers. Four haplotypes (Hap 45 to Hap 48) were observed in a newly identified lineage of S. cf. lamarrii (Lineage 2, L2)from the Ganga river. Four haplotypes (Hap 49 to Hap 52) were observed in Spereta sp. (Lineage 3, L3)collectedfrom the Brahmaputra and showed genetic similarity to species reported from the Mahanadi river. Two haplotypes (Hap 53 to Hap 54) were found in S. aorella (Lineage 4, L4) from the lower Ganga (Jharkhand) and Brahmaputra river (Tezpur, Assam). Twenty-nine haplotypes (Hap 55 to Hap 83) were found in S. aor (Lineage 5, L5) from the Ganga and Mahanadi rivers. Interestingly, the $S$. seenghala (Lineage 6, L6) sequences submitted by Kumari et al., (2016) from Brahmaputra (Raha, Assam) showed eight distinct haplotypes (Hap 84 to Hap 91) with unique genetic signature than rest of Spereta spp.

A high number of segregating sites was found in the $S$. lamarrii (77), whereas it was low in $S$. aorella (1) (Table 3). The haplotype diversity (hd) of $S$. lamarrii and $S$. aor were comparable and high $0.954 \pm 0.007$ and $0.937 \pm 0.015$, respectively, whereas it was low $(0.409 \pm 0.060)$ in $S$. aorella. The calculated nucleotide diversity $(\pi)$ was ranged from 0.0016 in $S$. cf. lamarrii to 0.025 in Spereta sp. lineage of Brahmaputra and Mahanadi rivers. The ratio of transition, transversion rate (Ts/Tv) and indel was varied among Spereta spp. (Table 3).

\section{Molecular phylogeny and haplotype network analysis}

The Bayesian consensus tree was generated using CR sequences to access the genetic relationships between all haplotypes belonging to different Spereta spp. collected from Ganga, Gomti, Mahanadi, and Brahmaputra river systems (Fig. 3). The phylogenetic tree showed the presence of six different lineages of Spereta. L1 represents the haplotypes of $S$. lamarrii, whereas the haplotypes of $S$. cf. lamarrii are considered L2 from lower Ganga stretch formed basal position with $S$. lamarrii. L3 consists of sequences of Spereta spp. collectedfrom Brahmaputra and Mahanadi (the generated sequences are validated from the CO/gene).

Moreover, we did not find any valid CR sequences representing the species $S$. seenghala in the GenBank database. L4 and L5 consist of haplotypes representing the species $S$. aorella and $S$. aor, respectively, whereas $L 6$ formed the most basal clade and not clustered with any Spereta spp. represents the Brahmaputra (Raha, Assam) river (Fig. 3).

The median-joining network of all generated haplotypes strongly indicated the presence of multiple lineages in Spereta from the studied river (Fig. 4). The clustering pattern obtained from network analysis is highly supportive of phylogenetic analysis. Among the haplogroup of S. lamarrii (L1), only a single haplotype (Hap 3) was shared between Ganga and Brahmaputra rivers. No haplotype sharing was found in Ganga and Gomti rivers. We also identified two novel haplotypes, namely Hap 40 and Hap 49 from the Brahmaputra river clustered with the haplotype of S. lamarrii from Ganga (L1) and Spereta sp. (L3) 
from Mahanadi river, respectively. In addition, one sample from the Ganga river represents Hap 53 shared with the $S$. aorella from the Brahmaputra river. The three sequences of S. seenghala (KT022199- KT022201) submitted by Kumari et al., 2016 from the Mahanadi river are clustered within the clade of S. aor (Fig 4).

The present findings demonstrated the presence of significant genetic differentiation between all recognized lineages of Sperata. The mean pairwise genetic distance between S. lamarrii and S. cf. lamarrii was $4.4 \%$. In contrast, it was high between the Sperata $s p$. represent L3 which showed $>6.7 \%$ and L6 showed $>19.7 \%$, than the other species of Sperata (Table 4). Similarly, the intra-specific pairwise distance was ranged from 0.00 for S. aorella to $2.2 \%$ for Sperata sp. represents L3.

\section{Demographic history}

The demographical dynamics of the Sperata spp. were inferred from the neutrality test and mismatch distributions (Table 3 and Fig.SF1). The significant negative Tajima's $D$ and Fu's Fs testsvalue was only observed in $S$. lamarrii (L1), whereas it was statistically not significant $(\mathrm{P}>0.10)$ for the rest of the lineages. The significant negative values for Tajima's $D$ and Fu's $F s$ in $S$. lamarrii inferred an excess of rare nucleotide site variants and showed population growth or selection. The mismatch distribution analysis of $S$. lamarrii populations also supported the demographic expansion forming the unimodal-shaped curve. The newly identified S. cf. lamarrii (L2) showed a unimodal shape with no significant value. The multimodal and ragged-shaped graph observed in lineages 3,5 and 6 suggested population demographic equilibrium. To assess the fitment of our data, we calculated the SSD and raggedness statistic (r-index) under the demographic expansion model for each lineage. However, these values were not statistically significant except Sperata sp. (L3) (Table 2).

\section{Discussion}

The genetic structure and diversity analysis of any species inhabiting under high threats provides us vital information for their development and effective management ${ }^{22}$. For effective conservation and to maintain the pure genetic stock, knowledge about the existing genetic lineages of species is essential. Previous studies on population genetics of Seenghala have not provided information on lineages and considered all Sperata spp. as one species i.e., Sperata seenghala from major Indian rivers ${ }^{7,8}$. During previous studies, whatever populations were present in Ganga, Mahanadi, Godavari, Narmada, and Brahmaputra were considered S. seenghala. Kumar et al. (2021) revealed that $S$. seenghala is endemic to the Krishna river basin. In the present study, we found that the sequences submitted by Kumari et al. (2017) matched with $S$. lamarrii and three sequences matched with $S$. aor. from the Mahanadi river, which might be the result of misidentification.

This study provides an extensive analysis of mtDNA CO/ and CR to understand the presence of genetic lineages and their population structure. To identify the species boundaries and presence of taxonomic units within the genus Spereta, we generated DNA barcode data from major Indian rivers. In addition, we generated the mtDNA CR data of $S$. aor and compared it with other existing populations of Sperata spp. Perviously, Kumar et al. (2021) described five valid Sperata species: $S$. lamarrii, S. seenghala, S. aorides, S. aorella and S. aor from the Indian subcontinent. Based on our species delimitation analysis, we identified the presence of seven Sperata lineages from the Indian subcontinent. Out of seven identified lineages, five correspond to previously described species as mentioned above ${ }^{3}$, while two represent the newly identified lineages from the Ganga river, which is close to $S$. lamarrii. Thus, we assigned it as $S$. cf. lamarrii, whereas the second lineage identified from Brahmaputra (Tezpur, Assam) and unknown locality of the Brahmaputra, Surma (Bangladesh), which was previously represented as S. cf. seenghala by Kumar et al., (2021); now assigned as Sperata sp. due to high sequences variations then S. seenghala. Conversely, the analysis of CR also indicated the presence of one more putative lineage from Raha, Assam of Brahmaputra river (sequences submitted by Kumari et al., 2017), which formed a basal clade with other identified Spereta spp. Combining the results of both regions (CO/and CR) of mtDNA, we identified the presence of at least eight putative Spereta lineages from Indian rivers.

The present study on genetic structure and differentiation among Spereta populations exhibited a high genetic differentiation between identified lineages. The level of genetic distance between S. lamarrivs. S.cf. lamarri and S. seenghala 
vs. Sperata sp. are comparatively higher than the value between $S$. seenghala and S. lamarri. Thus, based on species delimitation analysis and inter-specific mean pairwise genetic distances, $S$. cf. lamarrii and Sperata $s p$. genetically qualify the status of distinct species. The intra-specific pairwise genetic distance was highest $(0.4 \%)$ for Sperata $s p$, due to the presence of two samples from Tejpur, Brahmaputra river in this group, which is genetically more diverse and supported by species delimitation analysis based on bPTP and GMYC model.

The phylogenetic and pairwise genetic distance analysis using mtDNA CR indicated population structuring in Sperata spp. High haplotype diversity was observed in S. lamarrii (Lineage 1, L1) followed by S. aor (Lineage 5, L5), Sperata sp. (Lineage 6, L6) and S. cf. lamarrii (Lineage 2, L2); moderate in Sperata sp. (Lineage 3, L3); while, lowest in S. aorella (Lineage 4, L4). The phylogenetic and network analysis revealed that $S$. lamarrii $(\mathrm{L} 1)$ is widely distributed throughout the Ganga, Gomti and found in the Brahmaputra, whereas S. cf. lamarrii (L2) is confined to the lower stretch of Ganga, i.e, Munger district in Bihar to Jharkhand. In addition, $S$. aorella is also found in Ganges-Brahmaputra-Surma river basins in India and Bangladesh. As reported earlier by Kumar et al. (2021), the $S$. aor was widely seen in the Ganges-Brahmaputra-Surma river basins in India and Bangladesh, extending to the Godavari river and the Narmada basin in South India. Our genetic analysis indicated the presence of $S$. aorfrom the Mahanadi river, whereas a major population exists in the Ganga river. Thus our findings indicated that the Ganga river basin sustains the multiple gene pools of Sperata spp. The possible explanation for the existence of the Gomti and Brahmaputra lineages in the Ganga or vice versa is that the Gomti river confluences with Ganga at Saidpur, Kaithi, near Varanasi district, Uttar Pradesh. In contrast, Brahmaputra confluences at the Sunderbans area of Bangladesh provided the potential route for species dispersal.

However, when we compared our CR data with Kumari et al. (2017), samples of Mahanadi (L3) and Brahmaputra (L6) showed distinct clades in phylogenetic and network analysis. It was also supported by pairwise genetic distance using CR data, where genetic divergence between Ganga (L1)-Brahmaputra (L6) was (19.7\%) and between Ganga (L1)-Mahanadi (L3) was (7.1\%). Therefore, we report the presence of nine Sperata lineages from the Indian subcontinent, seven lineages based on DNA barcode data of CO/gene and two lineages based on CR data of Mahanadi and Brahmaputra rivers.

We collected a total of 30 specimens of Sperata spp. from the Brahmaputra river, where three samples (SS240-SS241, hap 40) were of S. lamarrii and two (SS243-SS244, hap49) samples were clustered with Mahanadi for CR data. However, COI data analysis showed samples SS243-SS244 (hap16) clustered with Sperata sp. (previously represented as S. cf. seenghala by Kumar et al. (2021). Moreover, we also recorded one specimen (SS245) of S. aorella from the lower stretch of Ganga, Sahebganj, district, Jharkhand. Interestingly, comparative analysis of the present study CR data with Kumari et al. (2017) showed two sequences (accession no. KT022220 and KT306656) from the Brahmaputra were merging with the S. Iamarrii, Ganga haplotype (Hap.3). In contrast, three sequences (accession no. KT022199, KT022220, and KT022201) from Mahanadi (Hap. 83) were clustered with S. aor of the Ganga river. It indicated that the Brahmaputra river also sustains the gene pool of the Ganga river. The possible explanation for the existence of the Brahmaputra lineage in the Ganga or vice versa is that their confluences in the Sunderbans provide a potential route for species dispersal. The genetic differentiation between Ganga S. Iamarrii (L1)-Brahmaputra (L6) was much higher (19.7\%) than the values observed between S. lamarrii (L1) and S. aor (L5) (14\%).

Moreover, the genetic distance between S. lamarrii (L1) and newly identified lineage S. cf. lamarrii (L2) of Ganga was $4.4 \%$ and it was $7.1 \%$ between S. lamarrii (L1) of Ganga and Mahanadi (L3). This result indicated the presence of a highly diverse lineage in the Brahmaputra (L6) than the $S$. lamarrii (L1), which needs to be confirmed based on their meristic and morphometric characters. Structuring in Sperata is supported by a previous RAPD based study where population substructuring was observed in Sutlej and Beas from the Indus river system ${ }^{15}$. The study on stock discrimination using microsatellite markers from the middle to lower stretch of river Ganga, i.e., Narora-Kanpur, Varanasi, and Bhagalpur, revealed three different stocks of $S$. aor ${ }^{17}$. However, this result was contradictory to our mtDNA-based study. We did not find any significant barrier to gene flow and structuring in $S$. aor across the sampling sites of the Ganga river. There are two distinct lineages in the Ganga river (S. lamarrii and S. cf. lamarrii), which are highly diverse than other lineages. The possible 
reason for multiple lineages in the stretch between Varanasi to Sahebganj of the Ganga river might be the confluence of several tributaries, i.e., Gomti, Ghaghara, Gandak, Son, Kiul and Kosi that might have resulted in the mixing of different gene pools. Hence, further inventory of Sperata species' presence in these tributaries needs to be explored. Recently, Acharya et al. (2019) reported population sub-structuring in the Brahmaputra, Ganga, Godavari, Mahanadi, and Narmada. The population sub-structuring might be due to distinct lineages in the studied population by Acharya et al. (2019) where all populations were considered one species, S. seenghala ${ }^{3}$. The results indicated the low genetic divergence between Ganga-Brahmaputra river basin than the Mahanadi river population, with comparatively low genetic diversity from the Ganga river.

Further, the present study showed that Ganga's $S$. lamarrii is genetically closer to Mahanadi than the Brahmaputra. It is also supported by a previous study using mtDNA cytochrome $b$ and $\mathrm{CR}^{7}$. It also appears that the Ganga and Mahanadi are geographically more isolated than the Brahmaputra and all three rivers are obviously on an independent evolutionary trajectory. However, our study indicated that Brahmaputra lineages qualify the species level variation and adequately address the highly diverse lineages among Spereta.

The significant negative Tajima's $D$ and Fu's Fs tests value was observed only in $S$. lamarrii (L1) from the rest of the lineages, which indicated an excess of rare nucleotide site variants and population expansion. Moreover, mismatch distribution analysis of S. lamarrii populations also supported the demographic expansion. However, non-significant Tajima's D and Fu's Fs tests suggested no historical reduction in effective population size in these rivers. The lineages L3, L5 and L6, showed multimodal and ragged-shaped graph in mismatch distribution analysis indicates the demographic stability or results of

population admixture in Spereta that could be due to their reliability with allopatric divergence ${ }^{24,25}$. The present genetic features in Ganga and other existing Spereta populations are the consequence of long-term geographical isolation and adaptation to the local environment.

\section{Conclusions}

This study revealed the existance of multiple Spereta lineages in the Indian River system. S. lamarrii was observed from Ganga, Gomti, and Brahmaputra river basins; and S. cf. lamarrii from the lower Ganga stretch. S. aorella was detected from Ganges-Brahmaputra-Surma river basins and $S$. seenghala from the Krishna river basin. $S$. aorides occurs in Cauvery and $S$. aor in Ganga and Mahanadi. In addition, two more lineages of Spereta spp. were detected, of which one is found in Brahmaputra and Mahanadi, and the second is seen in the Brahmaputra. This study indicated the presence of multiple genetic lineages of Spereta from Ganga-Gomti, Mahanadi, and Brahmaputra rivers that are considered a distinct Evolutionary Significant Unit (ESUs). These findings will help to understand the fish taxonomy, fish biology, and effective management and conservation of catfishes in Indian rivers. However, a detailed comparative morphological study with microsatellite data would significantly improve the understanding of the fish taxonomy, population genetic structure of genus Spereta.

\section{Materials And Methods}

We used 270 fin tissues samples of Sperata spp. from 13 geographic locations covering Ganga, Brahmaputra and Gomti rivers (Figure 1 and Table 1). Other sequences in the present analysis were downloaded from the NCBI database (http://www.ncbi.nlm.nih.gov/pubmed/) (Table ST1) 3,7,23. Samples were collected from the local fisherman and no live specimens were specifically captured for the experiment; therefore, Institutional Animal Ethics Committee approval was not required for the sampling. All methods were carried out in accordance with relevant regulations and ARRIVE guidelines (https://arriveguidelines.org). Samples were stored in 70\% ethanol for molecular study. Total genomic DNA was extracted from the tissue samples using the phenol-chloroform extraction protocols with a final elution volume of $100 \mu \mathrm{l}^{26}$. The extracted DNA was checked on $0.8 \%$ agarose gel, quantified in QIAxcel, and diluted in a final concentration of $30 \mathrm{ng} / \mu \mathrm{l}$ for PCR amplification. 


\section{PCR amplification and sequencing}

PCR amplification was performed using mtDNA COI primer Fish F1 (5' - TCA ACC AAC CAC AAA GAC ATT GGC AC - 3') - Fish R1 (5' - TAG ACT TCT GGG TGG CCA AAG AAT CA - 3') ${ }^{27}$ and CR primers SSDLoop F:5囚-CACCCCTAACTCCCAAAGC-3区, and

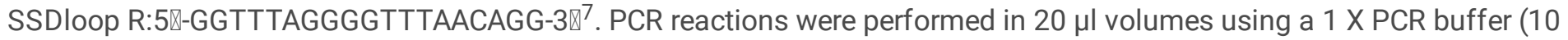
$\mathrm{mM}$ Tri $-\mathrm{HCl}, \mathrm{pH} 8.3$, and $50 \mathrm{mM} \mathrm{KCl}), 1.5 \mathrm{mM} \mathrm{MgCl} 2,0.2 \mathrm{mM}$ of each dNTP, 2 pmol of each primer, $5 \mathrm{U}$ of Taq DNA polymerase and $1 \mu \mathrm{l}(\sim 30 \mathrm{ng})$ of the template DNA. The PCR conditions were as follows: $95^{\circ} \mathrm{C}$ for 5 minutes, followed by 35 cycles of denaturation at $95^{\circ} \mathrm{C}$ for 45 seconds, annealing at $58^{\circ} \mathrm{C}$ for 45 seconds, and extension at $72^{\circ} \mathrm{C}$ for 75 seconds. The final extension was at $72^{\circ} \mathrm{C}$ for 10 minutes. The consistency of the PCR amplification was monitored using positive and negative controls. The PCR amplicons were electrophoresed on $2 \%$ agarose gel and visualized under the UV transilluminator. Exonuclease I (EXO- $I$ ) and shrimp alkaline phosphatase (SAP) treatments were given to the amplified PCR products (USB, Cleveland, $\mathrm{OH}$ ) for $15 \mathrm{~min}$ at $37^{\circ} \mathrm{C}$ and $20 \mathrm{~min}$ at $80^{\circ} \mathrm{C}$, to degrade any residual primer and dNTPs. The amplified PCR products were sequenced from forward and reverse directions using the BigDyeß Terminator kit (v3.1) and analyzed on an Applied Biosystems Genetic Analyzer ABI 3500XL.

\section{Data analysis}

The raw sequences obtained from the forward and reverse directions were aligned and edited with SEQUENCHER®Version 4.9 (Gene Codes Corporation, Ann Arbor, MI, USA) to get the consensus sequence. All the consensus sequences were aligned using the program CLUSTAL X multiple sequence alignment ${ }^{28}$ and examined by visual inspection.

\section{Species delimitation analyses using the DNA barcode}

Species delimitation tests were performed to confirm the presence of taxonomic units of Sperata spp. based on CO/gene. The tests were performed using five different approaches: I- Multi-rate Poisson Tree Processes (mPTP) ${ }^{29}$; II- Bayesian Poisson Tree Processes (bPTP) ${ }^{29}$; III- Generalized Mixed Yule-Coalescent (GMYC) ${ }^{30}$; Automatic Barcode Gap Discovery $(A B G D)^{31}$; and IV-Assemble Species by Automatic Partitioning (ASAP) ${ }^{32}$. These methods are widely accepted and best suited on DNA-barcoding data sets precisely because they do not require predefined species hypotheses ${ }^{32}$. The haplotype-based tree was collected from the phylogenetic analyses to perform species delimitation analyses. Two outgroup species, Bagrus ubangensis (KT192811) and Hemibagrus menoda (MK572258), were used to root the phylogenetic tree. The mPTP, bPTP, GMYC, ABGD and ASAP analyses were performed using web server https:// mptp.h-its.org; https://species.h-its.org, https://species.h-its.org/gmyc/; https://bioinfo.mnhn.fr/abi/public/abgd/abgdweb, and https://bioinfo.mnhn.fr/abi/public/asap/, respectively. We first employed the most popular GMYC and mPTP model to estimate the maximum likelihood delimitation from an inferred phylogenetic tree. Later, we added Bayesian support with bPTP, ABGD models. ASAP is a newly developed approach, implementing a hierarchical clustering algorithm that only uses pairwise genetic distances from single-locus sequence alignments. MEGA $X^{33}$ was used to estimate within-group pairwise genetic distance and between-group mean distance between the identified lineages of Spereta.

\section{Control region sequence diversity and population genetic structure}

DnaSP $5.0^{34}$ was used to analyze the haplotype diversity (h), nucleotide diversity (p), and polymorphic sites (s). The number of transition, transversion, insertion, and deletion (Indel) for each population was calculated using the Arlequin $3.5^{35}$. Phylogenetic analyses were conducted in BEAST ver $1.7^{36}$. The analysis ran as four simultaneous MCMC chains for 10 million generations, sampled every 100 generations, and used a burn-in of 5000 generations. The credibility of the results was assessed using Tracer v1.6. The first 10\% per run was discarded as burn-in. Maximum credibility trees were obtained with TreeAnnotator (implemented in BEASTver 1.7 Package). The final phylogenetic tree was visualized in FigTree v.1.4.4 (http://tree.bio.ed.ac.uk/software/figtree/). The best fit substitution model was determined using Mr Modeltest Version 3.7 (Posada and Crandall 1998) based on the Akaike Information Criterion (AIC). The chosen model was the Hasegawa-KishinoYano model (HKY) with a gamma distribution for (G). The spatial distribution of haplotypes was visualized by a median- 
joining (MJ) network, created with the PopART software ${ }^{37}$. The mean pairwise genetic distance within-group and betweengroup of Spereta were estimated using MEGA X ${ }^{33}$. DnaSP $5.0^{34}$ was used to generate the mismatch distribution plot for trends in spatial demography history of Spereta lineages. Besides, to determine the demography history of each lineage, we have performed the neutrality test, Tajima's $D^{38}$, Fu's Fs test ${ }^{39}$, the sum of squared deviations (SSD) and Raggedness index (r) under the demographic expansion model for each population using the program Arlequin $3.5^{35}$. The P-values were obtained by 1000 simulations based on a selective neutrality test.

\section{Declarations}

\section{Author Contributions}

SAH developed the project and acquired funds and permission for conducting the study. SKG, PY and AK conceptualized the methodological framework of the genetic and designed experiment. PY, AK and AM collected the biological samples. PY, AK, NY, and MB performed wet lab work. PY and JAJ verified the morphological feature of the fish. PY and AK performed the statistical analysis and wrote the manuscript. All authors approved the final version of the paper.

\section{Financial Disclosure}

This study was funded by the National Mission for Clean Ganga (NMCG), Ministry of Jal Shakti, Department of Water Resources, River Development \& Ganga Rejuvenationthrough grant number B/02/2015-16/1259/NMCG. The funders had no role in study design, data collection, analysis and decision to publish, or manuscript preparation.

\section{Competing Interests}

The author(s) declare no competing interests.

\section{Availability of data and materials}

Sequence data are available through NCBI GenBank (Accession No. OM220629-OM221168).

\section{References}

1. Talwar, P. K. \& Jhingharan, A. G. Inland fishes of India and adjacent countries, vol II. Oxford and IBH Publishing Co, New Delhi 19, 1158 (1991).

2. Ferraris, J. C. J. \& Runge, K. E. Revision of the South Asian Bagrid catfish genus Sperata, with the description of a new species from Myanmar. Proceedings of the California Academy of Sciences, 51(10), 397-424 (1999).

3. Kumar, R. G., Charan, R., Krishnaprasoon, N. P. and Basheer, V. S. Catfishes of the genus Sperata (Pisces: Bagridae) in India. Journal of Fish Biology, 98:456-469 (2021).

4. Mohanty, B. P., Paria, P., Das, D., Ganguly, S., Mitra, P., Verma, A. et al. Nutrient profile of giant river-catfish Sperata seenghala (Sykes). National Academy Science Letters. 35(3), 155-161 (2012).

5. Saigal, B. N. \& Motwani, M. P. Studies on the fishery and biology of the commercial catfishes of the Ganga river system I. Eirly Life-History, Bionomics and Breeding of Mystus (Osteobagrus) seenghala (Syke). Indian Journal of Fisheries. 8(1), 60-74 (1961).

6. Froese, R. \& Pauly, D. Species of Sperata in FishBase. Retrieved from http://www.fishbase.org. (2011).

7. Kumari, P., Pavan-Kumar, A., Kumar, G., Alam, A., Parhi, J., Gireesh-Babu, P. et al. Genetic diversity and demographic history of the giant river catfish Sperata seenghala inferred from mitochondrial DNA markers. Mitochondrial DNA Part A. 28(6), 920-926 (2017). 
8. Acharya, A. P., Pavan-Kumar, A. Gireesh-Babu, P. Joshi, C.G., Chaudhari, A. \& Krishna, G.. Population genetics of Indian giant river-catfish, Sperata seenghala (Sykes, 1839) using microsatellite markers. Aquatic Living Resources. 32, 4 (2019).

9. Mirza, M. R., H. Nawaz and Javed, M. N. A note on the fishes of genus Aorichthys with the description of a new subspecies from Pakistan. Pakistan Journal of Zoology. 24: 211-213 (1992).

10. Mirza, M. R. Checklist of freshwater fishes of Pakistan. Pakistan Journal of Zoology Supplement Series (3): 1-30 (2003).

11. Yadav, P., Tripathi, R.K. \& Mohindra, V. CmZNF384-like gene in hypoxia-tolerant Indian catfish, Clarias magur (Hamilton 1822) in hypometabolic states associated with acute hypoxia and summer aestivation. Agri Gene. 10, 1-11 (2018).

12. Yadav, P., Tripathi, R. K., Singh, R. K. \& Mohindra, V. Expression profile and in silico characterization of novel RTF2h gene under oxidative stress in Indian catfish, Clarias magur (Hamilton 1822). Molecular Biology Reports. 44(1), 63-77 (2017).

13. Gupta, S. Review on Sperata seenghala (Sykes, 1839), a freshwater catfish of Indian subcontinent. J Aquac Res Development. 6(290), 2 (2015).

14. Ward, R. D. Genetics in fisheries management. In: Marine Genetics. Springer, Dordrecht;. p. 191-201 (2000).

15. Saini, A., Dua, A. \& Mohindra, V. Genetic variability analysis of Giant river catfish (Sperata seenghala) populations from Indus river system by RAPD-PCR. Genetika. 46(8), 1102-1107 (2010).

16. Garg, R. K., Sairkar, P., Chouhan, S., Batav, N., Silawat, N., Sharma, R. et al. Characterization of genetic variance within and among five populations of Sperata seenghala (Skyes, 1839) revealed by random amplified polymorphic DNA markers. Journal of Genetic Engineering and Biotechnology. 12(1), 7-14 (2014).

17. Nazir, A. \& Khan, M. A. Stock discrimination of Sperata aor from river Ganga using microsatellite markers: implications for conservation and management. Aquatic Living Resources 30, 33 (2017).

18. Brown, W.M., George, M. \& Wilson, A.C. Rapid evolution of animal mitochondrial DNA. Proceedings of the National Academy of Sciences. 76(4), 1967-1971 (1979).

19. Hebert, P.D., Ratnasingham, S.\& De Waard, J.R. Barcoding animal life: cytochrome c oxidase subunit 1 divergences among closely related species. Proceedings of the Royal Society of London. Series B: Biological Sciences. 270, S96-S99 (2003).

20. Greenberg, B.D., Newbold, J.E. and Sugino, A. Intraspecific nucleotide sequence variability surrounding the origin of replication in human mitochondrial DNA. Gene, 21(1-2), 33-49 (1983).

21. Wan, Q. H., Wu, H., Fujihara, T. and Fang, S. G. Which genetic marker for which conservation genetics issue? Electrophoresis. 25(14), pp.2165-2176 (2004).

22. Gupta, S. K., Kumar, A., Angom, S., Singh, B., Ghazi, M. G. U., Tuboi, C. \& Hussain, S. A. Genetic analysis of endangered hog deer (Axis porcinus) reveals two distinct lineages from the Indian subcontinent. Scientific report. 8(1), 1-12 (2018).

23. Ahmed, M.S., Chowdhury, M.M.K. \& Nahar, L. Molecular characterization of small indigenous fish species (SIS) of Bangladesh through DNA barcodes. Gene, 684, 53-57 (2019).

24. Rogers, A. R. \& Harpending, H. Population growth makes waves in the distribution of pairwise genetic differences. Molecular biology and evolution, 9(3), 552-569 (1992).

25. Zhao, L., Zhang, J., Liu, Z., Funk, S. M., Wei, F., Xu, M., Li, M. Complex population genetic and demographic history of the Salangid, Neosalanx taihuensis, based on Cytochrome b sequences. BMC Evolutionary Biology. 8(1), 201 (2008).

26. Sambrook, J. E., Fritsch, E. F., Maniatis, T. Molecular Cloning: A Laboratory Manual 2nd edn Cold Spring Harbor Laboratory Press NY. (1989).

27. Ward, R.D., Zemlak, T.S., Innes, B.H., Last, PR \& Hebert, P.D. DNA barcoding Australia's fish species. Philosophical Transactions of the Royal Society B: Biological Sciences. 360(1462), 1847-1857 (2005). 
28. Thompson, J. D., Gibson, T. J., Plewniak, F., Jeanmougin, F. \& Higgins, D. G. The CLUSTAL_X windows interface: flexible strategies for multiple sequence alignment aided by quality analysis tools. Nucleic acids research. 25(24), 4876-4882 (1997).

29. Zhang, J., Kapli, P., Pavlidis, P. and Stamatakis, A. A general species delimitation method with applications to phylogenetic placements. Bioinformatics, 29(22), 2869-2876 (2013).

30. Pons, J., Barraclough, T.G., Gomez-Zurita, J., Cardoso, A., Duran, D.P., Hazell, S., Kamoun, S., Sumlin, W.D. \& Vogler, A.P. Sequence-based species delimitation for the DNA taxonomy of undescribed insects. Systematic biology, 55(4), 595-609 (2006).

31. Puillandre, N., Lambert, A., Brouillet, S. \&Achaz, GJME ABGD, Automatic Barcode Gap Discovery for primary species delimitation. Molecular ecology. 21(8), 1864-1877 (2012).

32. Puillandre, N., Brouillet, S. \& Achaz, G. ASAP: assemble species by automatic partitioning. Molecular Ecology Resources, 21(2), 609-620 (2021).

33. Kumar, S., Stecher, G., Li, M., Knyaz, C. \& Tamura, K. MEGA X: molecular evolutionary genetics analysis across computing platforms. Molecular biology and evolution. 35(6), 1547-1549 (2018).

34. Librado, P. \& Rozas, J. DnaSP v5: a software for comprehensive analysis of DNA polymorphism data. Bioinformatics. 25(11), 1451-1452 (2009).

35. Excoffier, L. \& Lischer, H. E. Arlequin suite ver 3.5: a new series of programs to perform population genetics analyses under Linux and Windows. Molecular ecology resources. 10(3), 564-567 (2010).

36. Drummond, A. J., Suchard, M. A., Xie, D. \& Rambaut, A. Bayesian phylogenetics with BEAUti and the BEAST 1.7. Molecular biology and evolution. 29(8), 1969-1973 (2012).

37. Leigh, J. W. \& Bryant, D. Popart: full-feature software for haplotype network construction. Methods in Ecology and Evolution. 6(9), 1110-1116 (2015).

38. Tajima, F. Statistical method for testing the neutral mutation hypothesis by DNA polymorphism. Genetics. 123(3), 585595 (1989).

39. Fu, Y. X. Statistical tests of neutrality of mutations against population growth, hitchhiking and background selection. Genetics, 147(2), 915-925 (1997).

\section{Tables}

Table 1. Sampling locations of Sperata spp. used in this study. N, number of samples. 


\begin{tabular}{|c|c|c|c|c|c|c|c|}
\hline Rivers & Species & $\begin{array}{l}\text { Map } \\
\text { Site* }\end{array}$ & Sampling sites & Sample ID & $\mathbf{N}$ & Latitude & Longitude \\
\hline \multirow{9}{*}{ Ganga } & S. lamarrii & 1 & Bijinor, Uttar Pradesh & SS01-SS021 & 21 & 29.3919 & 078.048 \\
\hline & S. lamarrii & 2 & Tigri Ghat, Uttar Pradesh & $\begin{array}{l}\text { SS022- } \\
\text { SS036 }\end{array}$ & 15 & 28.8164 & 078.146 \\
\hline & S. lamarrii & 3 & Narora, Uttar Pradesh & $\begin{array}{l}\text { SS037- } \\
\text { SS056 }\end{array}$ & 20 & 28.2164 & 078.380 \\
\hline & S. lamarrii & 4 & $\begin{array}{l}\text { Samshabad, Uttar } \\
\text { Pradesh }\end{array}$ & $\begin{array}{l}\text { SS057- } \\
\text { SS074 }\end{array}$ & 18 & 27.5570 & 079.515 \\
\hline & S. lamarrii & 5 & Kanpur, Uttar Pradesh & $\begin{array}{l}\text { SS075- } \\
\text { SS089 }\end{array}$ & 15 & 26.4765 & 080.368 \\
\hline & S. lamarrii & 6 & Varanasi, Uttar Pradesh & $\begin{array}{l}\text { SS090- } \\
\text { SS101 }\end{array}$ & 12 & 25.3225 & 083.134 \\
\hline & $\begin{array}{l}\text { S. cf. } \\
\text { lamarrii }\end{array}$ & 7 & Munger, Bihar & $\begin{array}{l}\text { SS116- } \\
\text { SS131 }\end{array}$ & 16 & 25.3732 & 086.458 \\
\hline & S. lamarrii & 8 & Sahebganj, Jharkhand & $\begin{array}{l}\text { SS102- } \\
\text { SS115 }\end{array}$ & 14 & 25.2511 & 087.660 \\
\hline & S. aorella & 8 & Sahebganj, Jharkhand & SS245 & 1 & 25.2511 & 087.660 \\
\hline \multirow{3}{*}{ Gomti } & S. lamarrii & 9 & Lucknow, Uttar Pradesh & $\begin{array}{l}\text { SS132- } \\
\text { SS139 }\end{array}$ & 8 & 26.8355 & 080.972 \\
\hline & S. lamarrii & 10 & Barabanki, Uttar Pradesh & $\begin{array}{l}\text { SS140- } \\
\text { SS148 }\end{array}$ & 9 & 26.6620 & 081.404 \\
\hline & S. lamarrii & 11 & Sultanpur, Uttar Pradesh & $\begin{array}{l}\text { SS149- } \\
\text { SS161 }\end{array}$ & 13 & 26.2705 & 082.076 \\
\hline \multirow{4}{*}{ Ganga } & S. aor & 1 & Bijinor, Uttar Pradesh & $\begin{array}{l}\text { SS162- } \\
\text { SS202 }\end{array}$ & 41 & 29.3919 & 078.048 \\
\hline & S. aor & 2 & Tigri Ghat, Uttar Pradesh & $\begin{array}{l}\text { SS203- } \\
\text { SS213 }\end{array}$ & 11 & 28.8164 & 078.146 \\
\hline & S. aor & 3 & Narora, Uttar Pradesh & $\begin{array}{l}\text { SS214- } \\
\text { SS225 }\end{array}$ & 12 & 28.2164 & 078.380 \\
\hline & S. aor & 6 & Varanasi, Uttar Pradesh & $\begin{array}{l}\text { SS226- } \\
\text { SS239 }\end{array}$ & 14 & 25.3225 & 083.134 \\
\hline \multirow{3}{*}{ Brahmaputra } & S. lamarrii & 12 & Tezpur, Assam & $\begin{array}{l}\text { SS240- } \\
\text { SS242 }\end{array}$ & 3 & 26.6161 & 92.7969 \\
\hline & Sperata spp. & 12 & Tezpur, Assam & $\begin{array}{l}\text { SS243- } \\
\text { SS244 }\end{array}$ & 2 & 26.6161 & 92.7969 \\
\hline & S. aorella & & Tezpur, Assam & $\begin{array}{l}\text { SS246- } \\
\text { SS270 }\end{array}$ & 25 & 26.6161 & 92.7969 \\
\hline
\end{tabular}

Table 2. Estimates of mean inter-specific and intra-specific (shaded) pairwise distances based on COI gene in Spereta species. 


\begin{tabular}{|c|c|c|c|c|c|c|c|}
\hline Species & 1 & 2 & 3 & 4 & 5 & 6 & 7 \\
\hline 1. Sperata lamarri & 0.001 & & & & & & \\
\hline 1. Spereta cf. lamarri & 0.017 & 0.001 & & & & & \\
\hline 1. Sperata seenghala & 0.015 & 0.023 & 0.000 & & & & \\
\hline 1. Sperata sp. & 0.019 & 0.027 & 0.018 & 0.004 & & & \\
\hline 1. Spereta aorella & 0.064 & 0.074 & 0.071 & 0.073 & 0.001 & & \\
\hline 1. Spereta aorides & 0.087 & 0.087 & 0.091 & 0.093 & 0.044 & 0.000 & \\
\hline 1. Spereta aor & 0.094 & 0.097 & 0.099 & 0.095 & 0.096 & 0.100 & 0.001 \\
\hline
\end{tabular}

Table 3. Estimates of genetic diversity for each lineage of Sperata.

\begin{tabular}{|c|c|c|c|c|c|c|}
\hline Parameters & $\begin{array}{l}\text { Sperata lamarrii } \\
\text { (Lineage 1) }\end{array}$ & $\begin{array}{l}\text { Sperata cf. } \\
\text { lamarrii } \\
\text { (Lineage 2) }\end{array}$ & $\begin{array}{l}\text { Sperata sp. } \\
\text { (Lineage 3) }\end{array}$ & $\begin{array}{l}\text { Sperata } \\
\text { aorella } \\
\text { (Lineage 4) }\end{array}$ & $\begin{array}{l}\text { Sperata aor } \\
\text { (Lineage 5) }\end{array}$ & $\begin{array}{l}\text { Sperata sp. } \\
\text { (Lineage 6) }\end{array}$ \\
\hline $\mathrm{n}$ & 177 & 14 & 24 & 26 & 81 & 23 \\
\hline$N_{h}$ & 44 & 4 & 4 & 2 & 29 & 8 \\
\hline$S$ & 77 & 4 & 61 & 1 & 46 & 68 \\
\hline Ts/Tv/indel & $52 / 16 / 10$ & $4 / 0 / 0$ & $47 / 7 / 7$ & $0 / 0 / 1$ & $38 / 6 / 4$ & $11 / 15 / 42$ \\
\hline $\mathrm{h}( \pm \mathrm{SD})$ & $0.954 \pm 0.007$ & $0.747 \pm 0.078$ & $0.699 \pm 0.060$ & $0.409 \pm 0.060$ & $0.937 \pm 0.015$ & $0.853 \pm 0.055$ \\
\hline$\pi( \pm S D)$ & $0.00571 \pm 0.0005$ & $0.00169 \pm 0.0003$ & $0.024 \pm 0.0033$ & $0.024 \pm 0.0033$ & $0.009 \pm 0.0008$ & $0.005 \pm 0.0015$ \\
\hline \multicolumn{7}{|c|}{ Neutrality and Mismatch analysis } \\
\hline $\begin{array}{l}\text { Tajima's D } \\
(P)\end{array}$ & $\begin{array}{l}-1.82223 \\
(0.006)\end{array}$ & $0.38966(0.696)$ & $1.647(0.963)$ & $0.000(1.00)$ & $\begin{array}{l}-0.262 \\
(0.436)\end{array}$ & $\begin{array}{l}-1.086 \\
(0.141)\end{array}$ \\
\hline Fu's Fs (P) & $-16.952(0.001)$ & $0.339(0.582)$ & $21.862(1.00)$ & $1.181(0.61)$ & $\begin{array}{l}-3.622 \\
(0.166)\end{array}$ & $\begin{array}{l}10.076 \\
(0.999)\end{array}$ \\
\hline $\operatorname{SSD}(\mathrm{P})$ & $0.002(0.41)$ & $0.006(0.62)$ & $0.181(0.00)$ & $0.008(0.15)$ & $0.010(0.57)$ & $0.044(0.62)$ \\
\hline r-index $(P)$ & $0.012(0.620)$ & $0.050(0.890)$ & $0.298(0.00)$ & $0.200(0.20)$ & $0.006(0.930)$ & $0.040(0.650)$ \\
\hline
\end{tabular}

Note: Sample size $(n)$; number of haplotypes $\left(N_{h}\right)$; segregating sites $(S)$; haplotype diversity $(h)$; nucleotide diversity $(\pi)$; transition (Ts); transversion (Tv); insertion and deletion (indel); Standard diversity (SD); sum of square deviation (SSD); raggedness index ( $r$ ) 
Table 4. Estimates of mean inter-specific and intra-specific (shaded) pairwise distances based on CR region in Spereta species.

\begin{tabular}{|llllllll|}
\hline Species & Lineage & $\mathbf{1}$ & $\mathbf{2}$ & $\mathbf{3}$ & $\mathbf{4}$ & $\mathbf{5}$ & $\mathbf{6}$ \\
\hline Sperata lamarrii & lineage 1 & $\mathbf{0 . 0 0 6}$ & & & & & \\
\hline Sperata cf. lamarrii & lineage 2 & 0.044 & $\mathbf{0 . 0 0 2}$ & & & & \\
\hline Sperata sp. & lineage 3 & 0.071 & 0.067 & $\mathbf{0 . 0 2 2}$ & & & \\
\hline Sperata aorella & lineage 4 & 0.112 & 0.121 & 0.121 & $\mathbf{0 . 0 0 0}$ & & \\
\hline Sperata aor & lineage 5 & 0.141 & 0.140 & 0.134 & 0.142 & $\mathbf{0 . 0 1 0}$ & \\
\hline Sperata sp. & lineage 6 & 0.197 & 0.198 & 0.202 & 0.216 & 0.215 & $\mathbf{0 . 0 0 5}$ \\
\hline
\end{tabular}

\section{Figures}

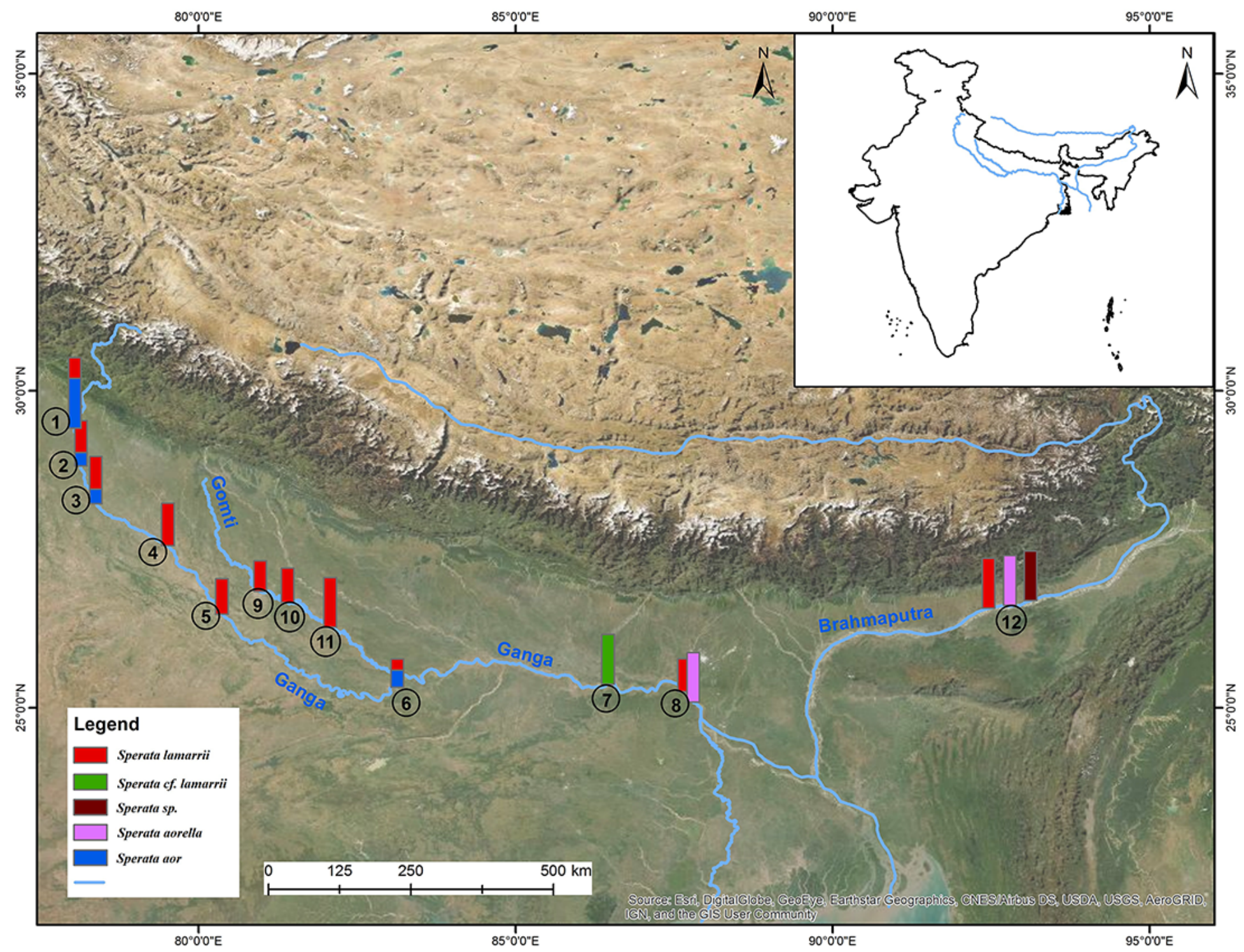

Figure 1 
Map showing the sampling sites of Spereta from the Ganga, Gomti, and Brahmaputra rivers used in this study. The details of sampling sites (1-12) are mentioned in Table 1.

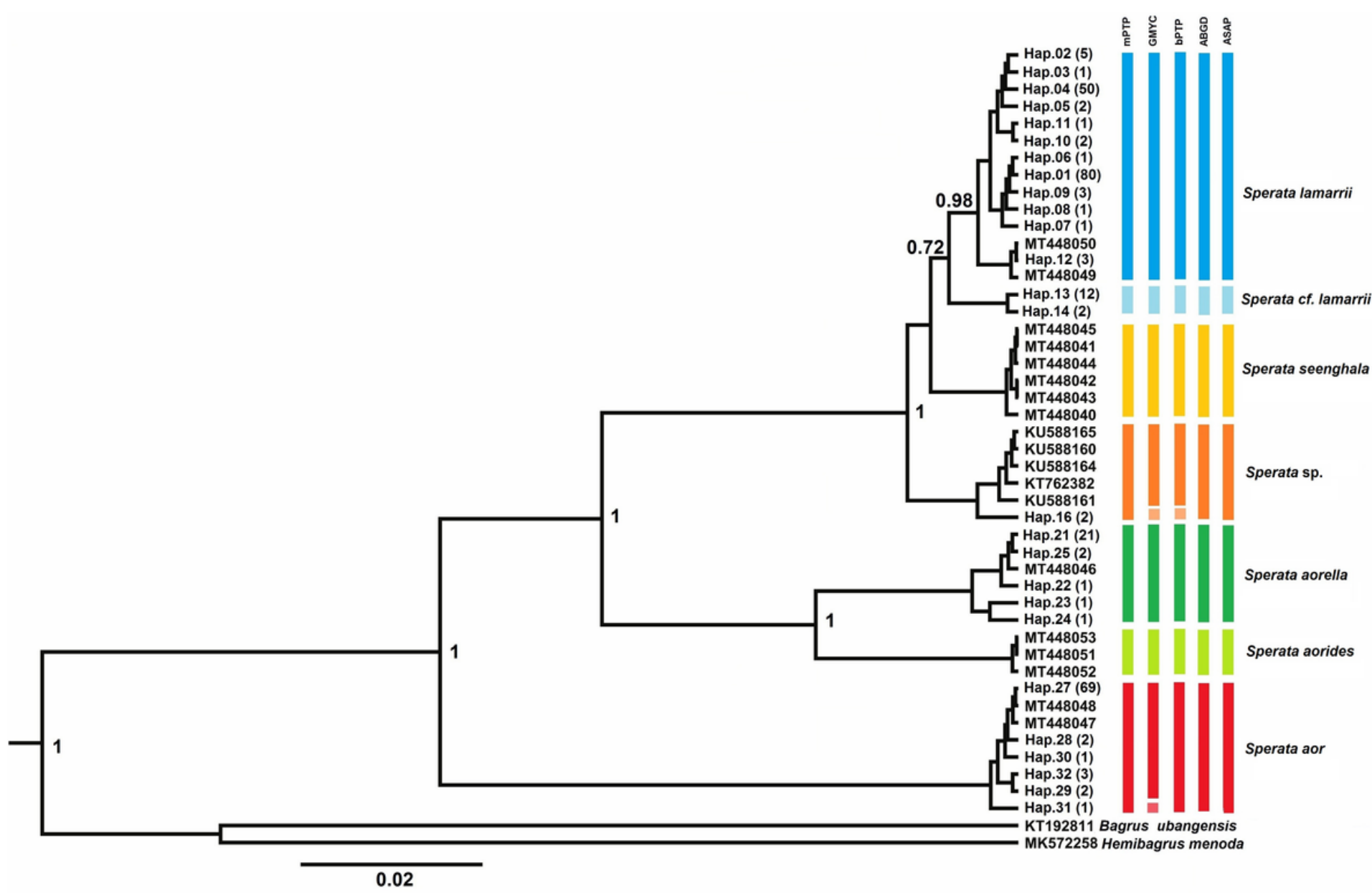

Figure 2

mtDNA CO/gene based Bayesian phylogeny of Spereta representing the result of species delimitation based on five different approaches: I- Multi-rate Poisson Tree Processes (mPTP); Generalized Mixed Yule-Coalescent (GMYC); Bayesian Poisson Tree Processes (bPTP); Automatic Barcode Gap Discovery (ABGD); and Assemble Species by Automatic Partitioning (ASAP). 


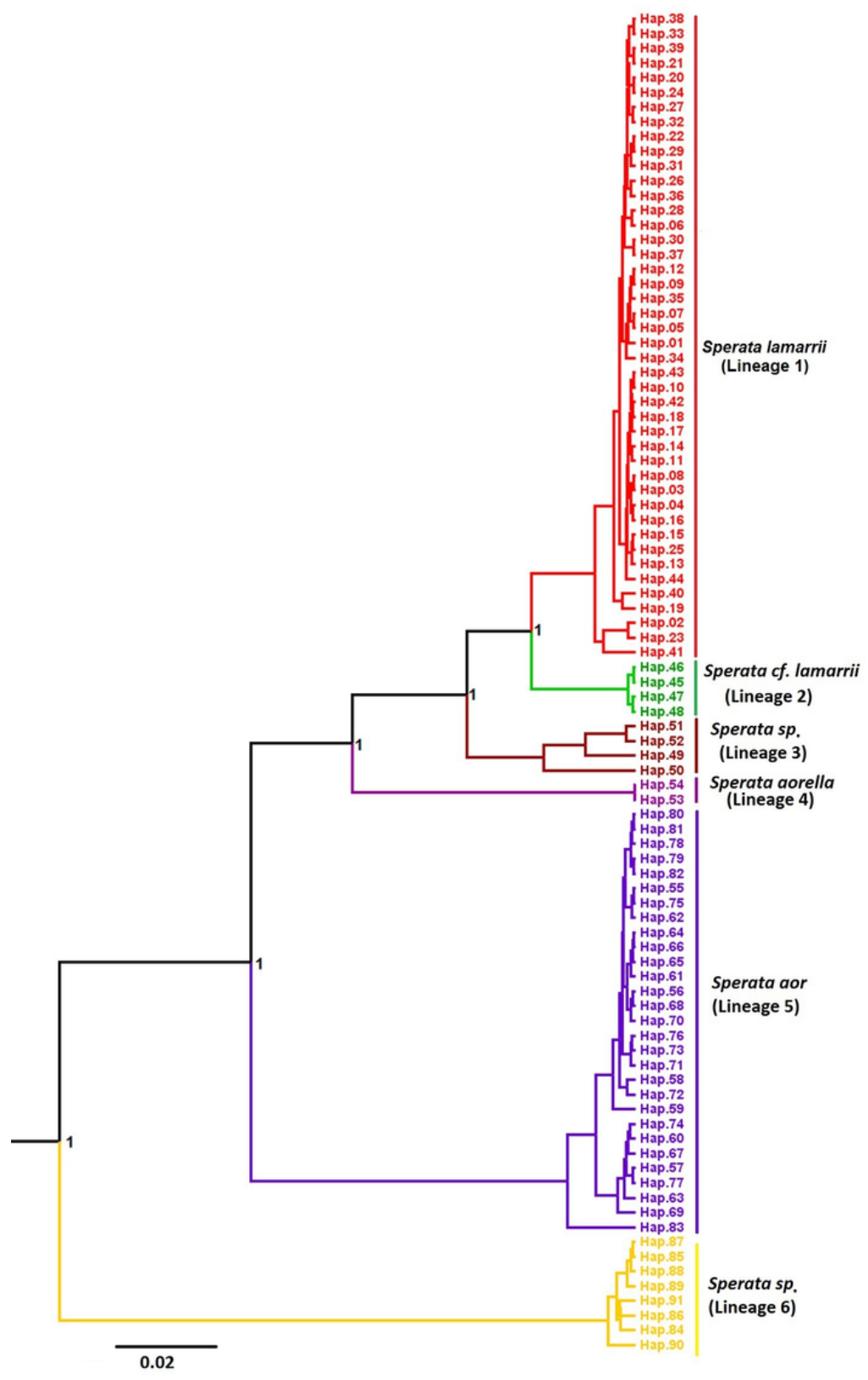

Figure 3

mtDNA control region based Bayesian tree for the phylogenetic resolution between the Spereta species. The numeric value at each node represents the posterior probability. 


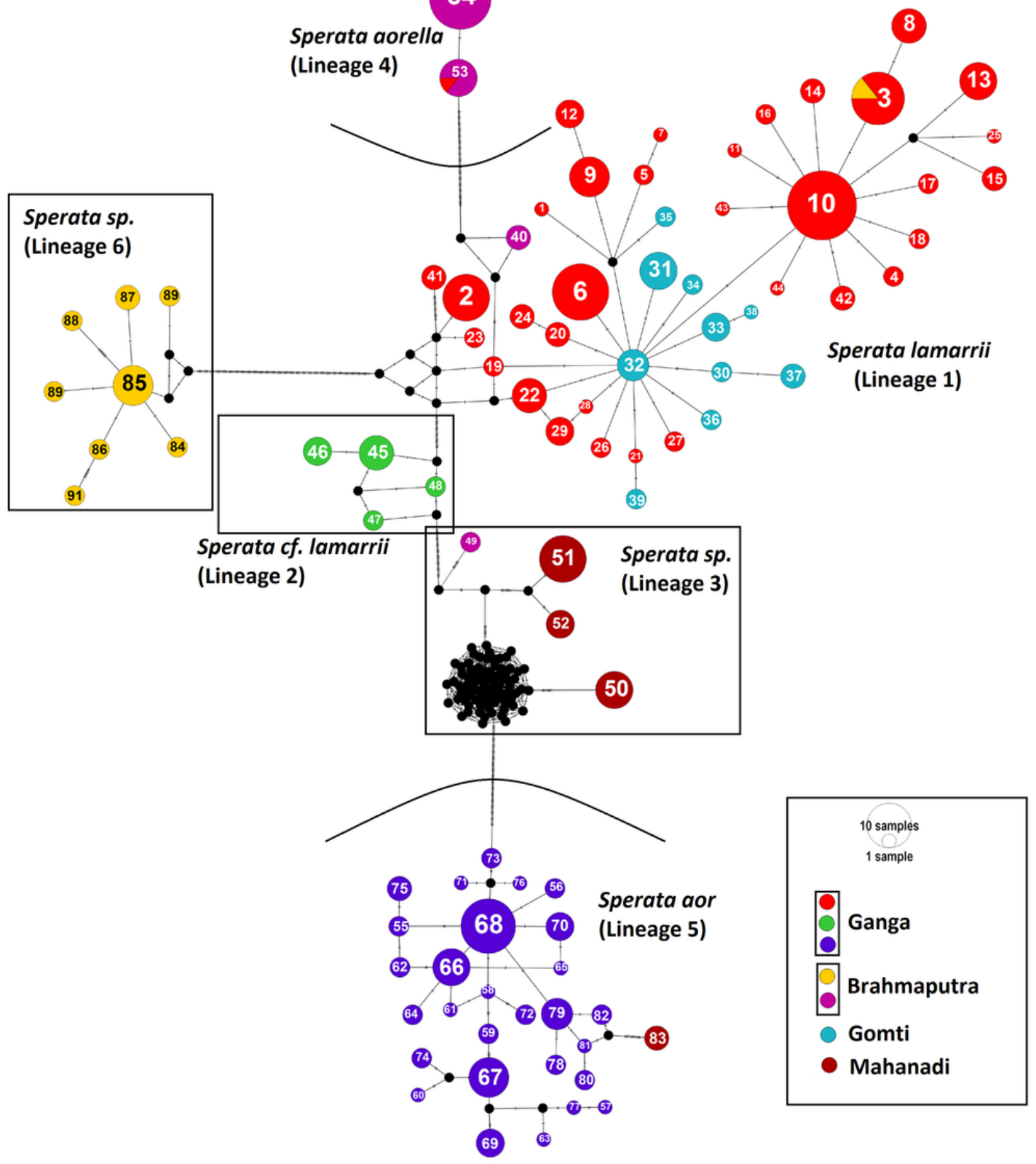

Figure 4

mtDNA control region based median-joining network of Sperata species indicates the presence of six distinct lineages. Lineage 1 consists of haplotypes of $S$. lamarrii; Lineage 2 consists of newly identified S. cf. lamarrii, Lineage 3 belongs to Spereta sp. and Lineage 4 consists of haplotypes of $S$. aorella, Lineage 5 represents $S$. aor; and Lineage 6 consists of haplotypes of Spereta sp. limited to Brahmaputra river. Circles represent haplotypes, circle size represents the number of individuals, and hash marks denote mutational steps.

\section{Supplementary Files}

This is a list of supplementary files associated with this preprint. Click to download.

- SupplementaryMaterialST1SF1.docx

- SupplimentryTableST2.xls 
- SupplimentryTableST3.xls

Page 18/18 